\title{
PERANCANGAN POSTER SEBAGAI MEDIA EDUKASI PESERTA DIDIK
}

\author{
Ismail Bambang Subianto ${ }^{1}$, Puji Anto ${ }^{2}$, Taufiq Akbar ${ }^{3}$ \\ Program Studi Desain Komunikasi Visual \\ Fakultas Bahasa dan Seni Universitas Indraprasta PGRI \\ ismail.bambangs@unindra.ac.id ${ }^{1}$,pujianto@unindra.ac.id ${ }^{2}$, grapickology.ta@gmail.com ${ }^{3}$
}

\begin{abstract}
Abstrak
Tujuan perancangan poster ini menghasilkan sebuah perancangan poster dengan menggunakan desain dan bahasa yang tepat, sehingga menghasilkan sebuah produk yang bermanfaat dan tepat sasaran sesuai. Metode pelaksanaan dilakukan dengan cara diantaranya, survei dan observasi, identifikasi masalah, rumusan masalah, penentuan konten, media, dan bahasa, penentuan desain poster, dan penempatan poster. Hasil dari kegiatan ini adalah tiga buah poster, yaitu poster tentang kerapihan, narkoba, dan janji siswa. Konsep desain ilustrasi yang diterapkan adalah gaya ilustrasi realistis. Gambar dibuat seperti aslinya sesuai anatomi dan proporsinya.Penggunaan huruf pada poster ini lebih mengutamakan readability (keterbacaan sebuah huruf) yang tinggi. Oleh sebab itu, kami memilih jenis huruf sans-serif bernama Franklin Gothic. Huruf sans-serif adalah huruf yang tidak memiliki kait/ kaki dan secara kontur hurufnya, huruf ini lebih modern dibanding huruf yang memiliki serif/ kait/ kaki. Konsep layout/ tata letak poster dipilih Picture Window Layout dimana jenis layout ini, tampilan gambar yang besar menjadi ciri khas utama dan diikuti dengan headline. Warna utama digunakan warna-warna dingin, seperti biru dan biru muda, agar tampilan poster ini lebih nyaman dipandang mata.
\end{abstract}

Kata Kunci: Poster, Media, Edukasi

\begin{abstract}
The purpose of this poster design produced a poster design by using design and precise language, so as to produce a useful product and targeted accordingly. The method of implementation is done by means of which, surveys and observation, problem identification, formulation of the problem, determination of content, media, and language, the determination of poster design, and placement of posters. The results of this activity are three posters, the poster about neatness, drugs, and the promise of the students. Concept illustration design adopted is realistic illustration style. Image made like the original in accordance anatomy and proportion. The use of letters on this poster prefers readability (readability of a letter) is high. Therefore, we chose a sans-serif typeface named Franklin Gothic. Sans-serif letters are letters that do not have a hook/leg and contours of the letter, this letter is more modern than the letters that have serif/ hooks/ foot. The concept layout/layout poster selected Picture Window Layout where this type of layout, see the big picture and the main characteristic was followed by headline. The main colors used cool colors, such as blue and light blue, in order to see this poster is more comfortable to the eye.
\end{abstract}

Keywords: Poster, Media, Education 


\section{PENDAHULUAN}

Berhubungan dengan peningkatan kualitas peserta didik, SMK Purnama Mandiri terus membenahi diri. Sesuai dengan misi SMK Purnama Mandiri, yaitu "Menyelenggarakan pendidikan yang berkualitas melalui pendidikan akhlak mulia dan penguasaan dasar-dasar ilmu pengetahuan serta penanaman semangat pembaharuan dalam mempersiapkan lulusan yang menguasai ilmu pengetahuan dan teknologi". Manajemen sekolah terus berinovasi agar terwujud- nya misi tersebut. Manajemen sekolah dalam hal ini adalah kepala sekolah sedang meningkatkan kualitas pendidikan dengan berbasis teknologi. Segala bentuk informasi yang berkaitan dengan edukasi terhadap peserta didik akan dikemas dalam bentuk media penyajian yang menarik, yaitu dengan melibatkan lembaga-lembaga yang kompeten terkait penggunaan media tersebut.

Berikut beberapa gambar yang menunjukkan belum adanya media visual yang dirancang secara baik berhubungan dengan program sekolah:

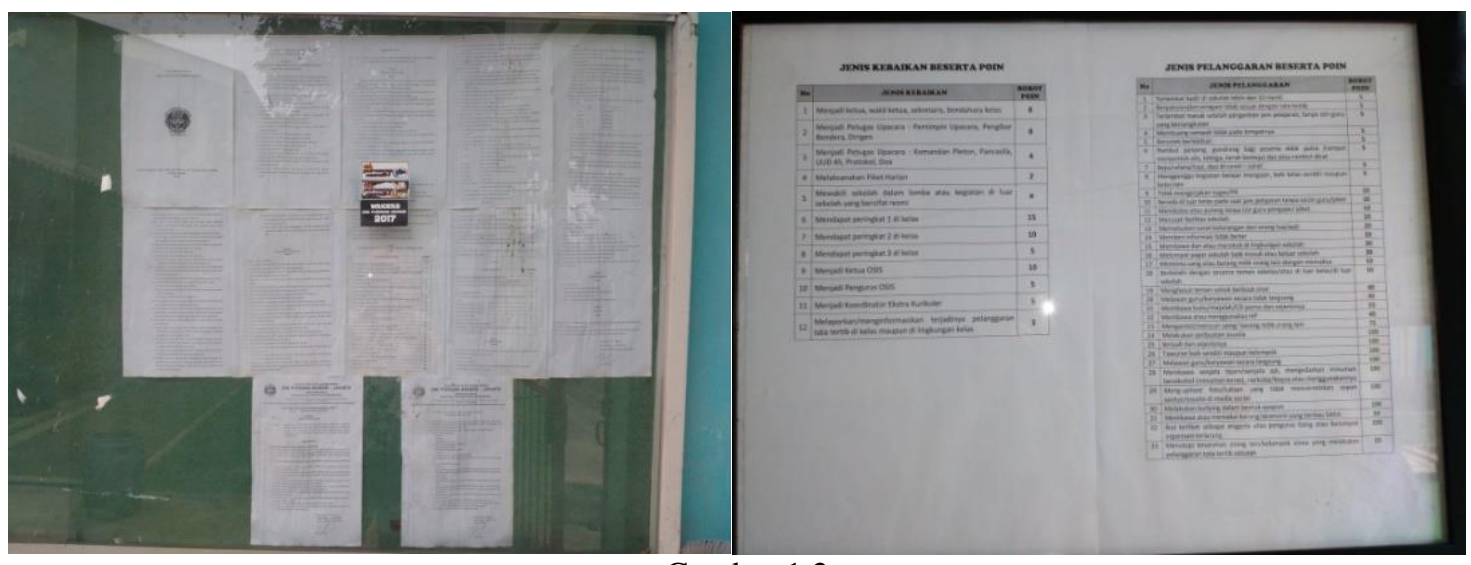

Gambar 1.2

Media Informasi Tata Tertib Sekolah

Sumber: Dokumen Pribadi

Salah satu prioritas kepala sekolah kaitannya dengan misi adalah mewujudkan pendidikan akhlak mulia. Penanaman akhlak mulia tidak hanya dilakukan dengan ceramah-ceramah keagamaan atau hanya berkaitan dengan ritual keagamaan. Kedisplinan, kerapihan, bekerja sama, dan menghindari narkoba, itu merupakan katagori akhlak yang mulia. Akhlak mulia bisa terbentuk melalui proses edukasi yang menggunakan media-media kekinian atau media desain yang bagus dan bahasa yang baik. Penggunaan media yang bagus dan bahasa yang baik serta penempatan media yang tepat, akan mampu memunculkan daya tarik peserta didik untuk selalu membaca dan pada akhirnya nanti termotivasi untuk melakukannya. Penggunaan metode tersebut, manajemen sekolah khususnya guru terbantu dalam proses belajar mengajar. Media tersebut nantinya akan menjadi salah satu bentuk transfer ilmu pengetahuan yang bisa mengoptimalkan proses belajar-mengajar. Media kekinian menjadikan proses pendidikan itu lebih menarik dan menyenangkan. Proses yang menarik dan menyenangkan, maka akan membuat suasana hati peserta didik lebih terbuka untuk menerima segala bentuk informasi apa pun. Akhinya, dengan adanya informasi yang terserap dengan baik, maka akan terbentuklah peserta didik yang berakhlak mulia. 
Berikut adalah gambar yang mencerminkan salah satu perilaku warga sekolah yang menjadi permasalah mitra:

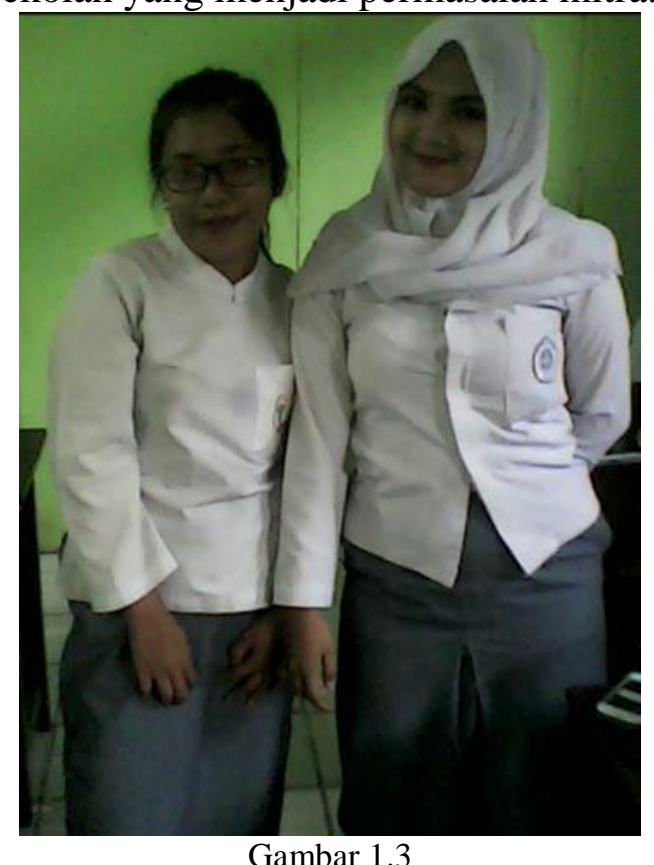

Perilaku peserta didik yang kurang baik Sumber: Dokumen Pribadi

Dari gambar di atas terlihat baju seragam peserta didik yang kurang sopan (terlalu ketat).

Oleh karena itu, tim pelaksana yang terdiri dari kompetensi di bidang bahasa Indonesia dan Desain Komunikasi Visual, bekerja sama untuk mewujudkan misi sekolah tersebut. Kompetensi Desain Komunikasi Visual adalah suatu disiplin ilmu yang mempelajari konsepkonsep komunikasi serta ungkapan kreatif melalui berbagai media untuk menyampaikan pesan dan gagasan secara visual dengan mengelola elemen-elemen grafis yang berbentuk gambar, tatanan huruf, warna, dan layout (Kusrianto, 2007: 2). Jadi, dengan keahlian DKV yang dimiliki oleh tim pelaksana, akan membuat sebuah konsep desain poster yang menggabungkan beberapa unsur sehingga sanggup menyampaikan pesan dengan baik. Dalam penyampaian pesan perlu adanya saluran yang berupa bahasa. Menurut Zaimar dan Harahap (2011: 56), Bahasa Indonesia dalam telaah wacana disebutkan jenis wacana menurut fungsi bahasanya, yaitu:

1. fungsi bahasa Referensial

Fungsi bahasa referensial adalah pengirim pesan tidak ingin tampil, melainkan ia ingin menonjolkan acuan atau hal yang dibicarakan.

2. fungsi bahasa ekspresif

Fungsi bahasa ekspresif berpusat pada pengirim pesan. Pengirim pesan mengemukakan gagasan terhadap isi pesan.

3. fungsi bahasa konatif

Fungsi bahasa konatif adalah fungsi bahasa yang digunakan apabila si pengirim ingin mempengaruhi si penerima.

4. fungsi bahasa fatik

Fungsi bahasa fatik berpusat pada saluran komunikasi. Semua unsur bahasa menunjukkan hubungan baik antara pengirim dan penerima.

5. fungsi bahasa puitik

Fungsi bahasa puitik adalah tambahan unsur keindahan dalam menyampaikan pesan.

6. fungsi bahasa metalinguistik

Fungsi bahasa metalinguistik berpusat pada kode. Metalinguistik dalam pelajaran bahasa berbentuk tanya-jawab antara pengirin dan penerima.

Jadi, dengan menggunakan fungsifungsi bahasa di atas, segala bentuk pesan akan tersampaikan dengan baik.

Berdasarkan analisis situasi di atas, timbul permasalah pada mitra, yaitu realisasi misi sekolah dengan berbasis teknologi. Misi yang dimaksud adalah berkaitan dengan akhlak mulia. Selama ini, SMK Purnama Mandiri melakukan proses belajar-mengajar hanya dengan metode ceramah. Lebih spesifik lagi, tata tertib yang secara tidak langsung merupakan tuntunan peserta didik untuk berperilaku di lingkungan sekolah, disajikan hanya dalam bentuk teks biasa dan hanya ditempel di mading sekolah. 
Tingkat keterbacaannya pun sangat minim. SMK Purnama Mandiri juga melakukan dokumentasi surat perjanjian tata tertib yang ditandatangani oleh peserta didik. Faktanya dokumen pernjajian hanya sebatas dokumentasi sehingga peserta didik masih banyak melakukan pelanggaran tata tertib.

Oleh sebab itu, Tim pelaksana dan mitra menyepakati untuk membuat media edukasi terhadap peserta didik berbasis teknologi, dalam hal ini menggunakan media dengan kompetensi dalam bidang desain. Desain media yang menarik, diharapkan segala bentuk permasalah yang berhubungan dengan akhlak mulia yang tuntunannya adalah tata tertib sekolah akan bisa terwujud. Disepakati pula tema-tema yang akan diprioritaskan lebih dahulu, di antaranya tema tentang kedisplinan, kerapihan, kerja sama, dan narkoba.

Berdasarkan latar belakang di atas, maka rumusan masalahnya adalah bagaimana merancang poster sebagai media edukasi terhadap peserta didik di SMK Purnama Mandiri.

Tujuan perancangan poster ini menghasilkan sebuah perancangan poster dengan menggunakan desain dan bahasa yang tepat, sehingga menghasilkan sebuah produk yang bermanfaat dan tepat sasaran sesuai dengan misi SMK Purnama Mandiri.

Metode pelaksanaan yang akan ditetapkan dalam program pengabdian kepada masyarakat ini dilakukan melalui beberapa tahap, yaitu:

1. Metode pelaksanaan IbM ini yang pertama adalah melakukan survei dan observasi pada mitra. Hal ini dilakukan untuk mengidentifikasi perilaku warga sekolah, khususnya peserta didik.

2. Selanjutnya adalah ditemukannya beberapa masalah di SMK Purnama Mandiri, di antaranya: belum adanya media visual untuk menyampiakan informasi dan adanya perilaku peserta didik yang banyak melanggar aturanaturan atau tata tertib sekolah.

3. Menentukan konten apa yang menjadi prioritas utama sekolah. Hasilnya, ditentukanlah konten yang berhubungan dengan misi sekolah yaitu menjadikan peserta didik berakhlak mulia, dengan acuan tata tertib sekolah.

4. Menyepakati media apa yang akan digunanakan untuk menyampaikan konten tersebut. Akhirnya, disepakati penggunaan media poster dengan tema tentang kedisplinan, kerapihan, kerja sama, dan narkoba.

5. Menetapkan pilihan bahasa sesuai fungsi bahasa referensial, konatif, dan ekspresif. Melalui fungsi bahasa tersebut tim dan mitra mencoba mempengaruhi peserta didik dengan poster untuk bertingkah laku di lingkungan sekolah sesuai dengan tata tertib yang ada.

6. Langkah selanjutnya adalah proses perancangan konsep desain yang akan diaplikasikan dam poster dengan tujuan pesan yang akan disampaikan dapat diterima dengan baik.

7. Produk IbM ini adalah poster edukasi. Spesifikasi karya yang akan dihasilkan adalah kombinasi antara penggunaan teks/bahasa dengan visual, kemudian dicetak dengan ukuran A2 dan A3. Pencetakan dan framing dilakukan melalui jasa percetakan.

8. Setelah semua tahapan dilalui, maka langkah selanjutnya adalah penyerahan dan penempatan poster di lokasi yang tepat.

9. Evaluasi program IbM ini akan dilakukan oleh pihak mitra dan tim pengusul selama kurun waktu satu semester. 


\section{PEMBAHASAN}

Hasil dalam kegiatan pengabdian kepada masyarakat dengan judul "Perancangan Poster sebagai Media Edukasi Terhadap Peserta Didik ini adalah tiga buah poster. Poster yang pertama adalah berisi tentang kesadaran peserta didik untuk memakai baju sekolah yang sesuai dengan ketentuang yang ada. Poster yang kedua berisi tentang bahayanya narkoba terhadap generasi muda khususnya peserta didik dalam menunjang prestasi. Poster ketiga berisi tentang janji siswa SMK Purnama Mandiri. Janji siswa ini dibuat dengan alasan sebagai bentuk doktrin terhadap peserta didik, agar isi janji siswa tersebut melekat dalam diri peserta didik.

Berikut merupakan konsep media yang digunakan dalam perancangan poster tentang kerapian dalam berbusana khususnya seragam sekolah, narkoba, dan janji siswa.

\section{Tahap Pembuatan Ilustrasi Poster}

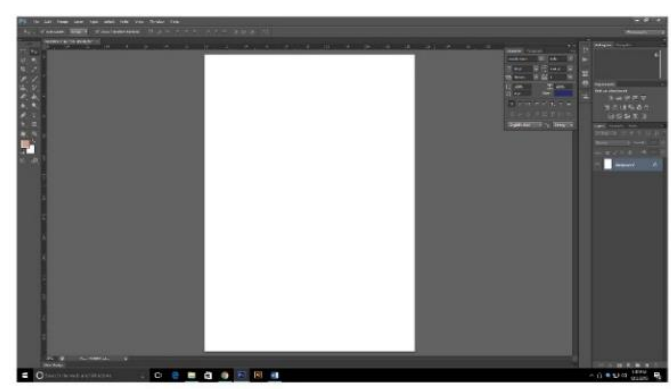

Gambar 5.1

Tampilan Interface Software Adobe Photoshop Sumber: Dokumen Pribadi

Ilustrasi adalah hasil visualisasi dari suatu tulisan dengan teknik drawing, lukisan, fotografi, atau teknik seni rupa lainnya yang lebih menekankan hubungan subjek dengan tulisan yang dimaksud daripada bentuk. Tujuan ilustrasi adalah untuk menerangkan atau menghiasi suatu cerita, tulisan, puisi, atau informasi tertulis lainnya. Diharapkan dengan bantuan visual, tulisan tersebut lebih mudah dipahami. Gaya ilustrasi yang coba diterapkan pada poster ini adalah gaya ilustrasi realistis, dimana gambar yang dibuat seperti aslinya sesuai anatomi dan proporsinya.
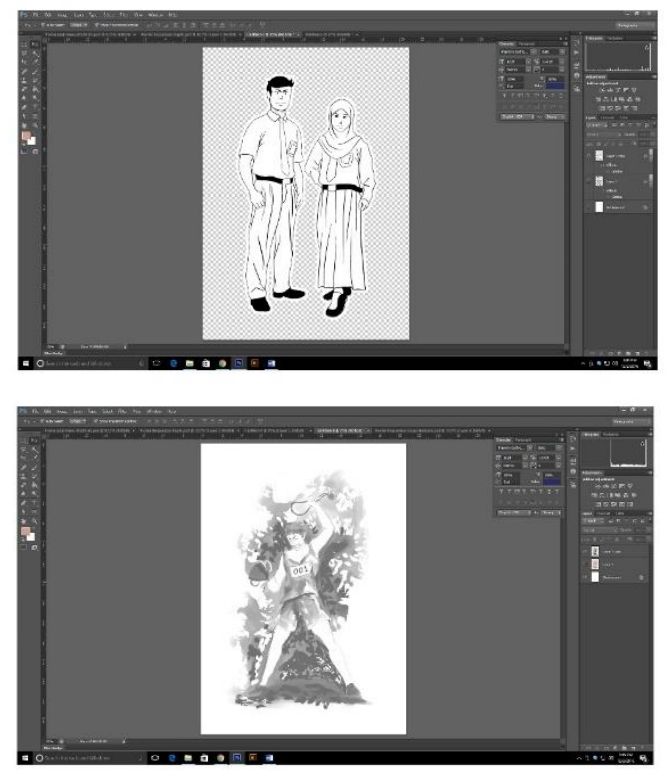

Gambar 5.2

Hasil scan ilustrasi manual menjadi format digital

Sumber: Dokumen Pribadi

\section{Tahap Pewarnaan Digital}
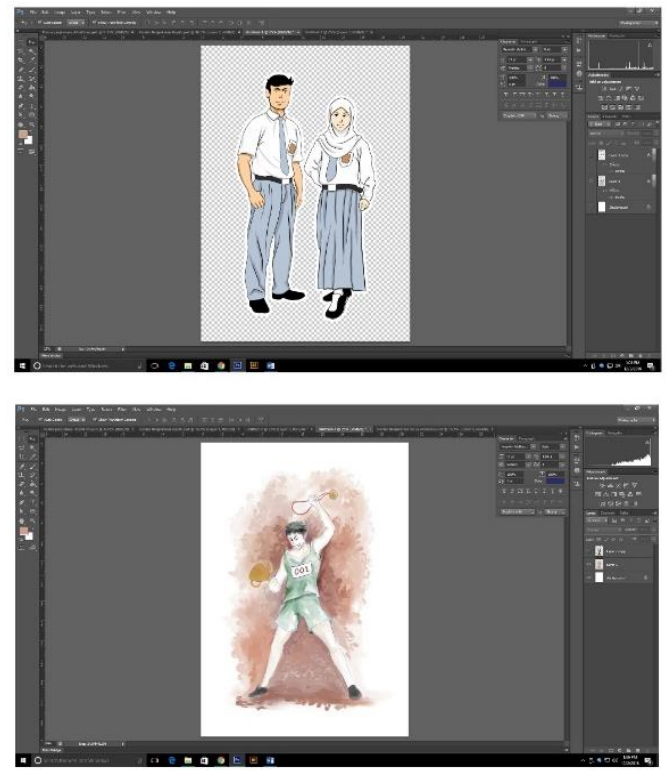

Gambar 5.3

Tahapan pewarnaan ilustrasi secara digital Sumber: Dokumen Pribadi 
Pada tahapan ini, ilustrasi dibuat secara manual terlebih dahulu diatas kertas. Kemudian setelah hasil sketsa selesai, ilustrasi tadi di-scan untuk mendapatkan file ilustrasi dalam bentuk digital. Tahapan pewarnaan dilakukan secara digital guna mempermudah pengerjaan dan lebih beragam warna yang bisa digunakan. Untuk pewarnaan, dipilih mode warna CMYK dan Pantone serta mengombinasikan mode warna tersebut dengan berbagai efek pewarnaan.

\section{Tahap Layout Poster}
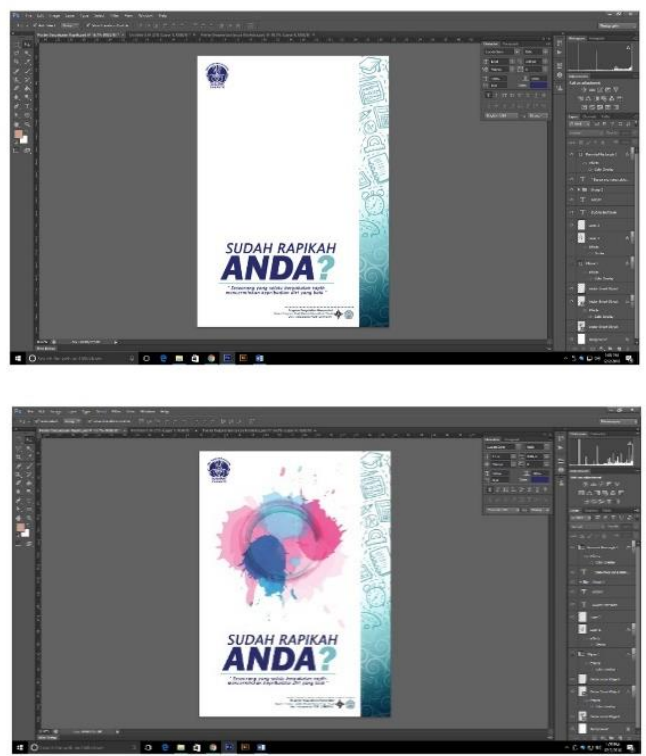

Gambar 5.4

Tahapan me-layout poster Sumber: Dokumen Pribadi

Pada tahapan ini, semua elemen desain seperti ilustrasi, tipografi, bidang, dan warna dikomposisikan menjadi satu sehingga menghasilkan susunan yang baik. Penggunaan huruf pada poster ini lebih mengutamakan readability (keterbacaan sebuah huruf) yang tinggi. Oleh sebab itu, kami memilih jenis huruf sans-serif bernama Franklin Gothic. Huruf sans-serif adalah huruf yang tidak memiliki kait/kaki dan secara kontur hurufnya, huruf ini lebih modern dibanding huruf yang memiliki serif/kait/kaki.

Untuk layout/tata letak poster kami memilih Picture Window Layout dimana jenis layout ini, tampilan gambar yang besar menjadi ciri khas utama dan diikuti dengan headline, keterangan gambar yang memiliki porsi yang kecil. Warna utama digunakan warna-warna dingin, seperti biru dan biru muda, agar tampilan poster ini lebih nyaman dipandang mata.

\section{Hasil Perancangan Poster dan Framing}

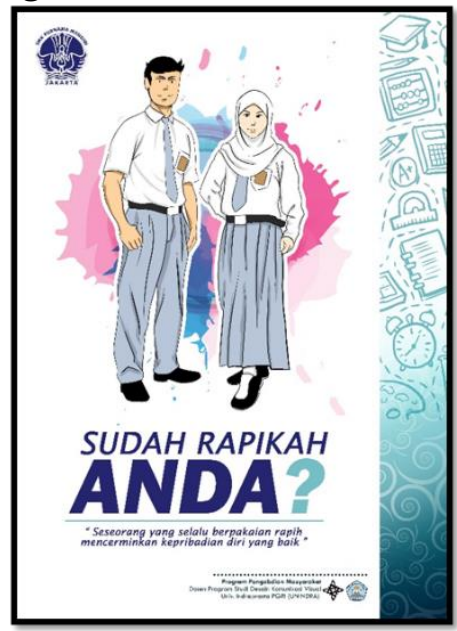

Gambar 5.5

Poster Tentang Kerapian

Sumber: Dokumen Pribadi

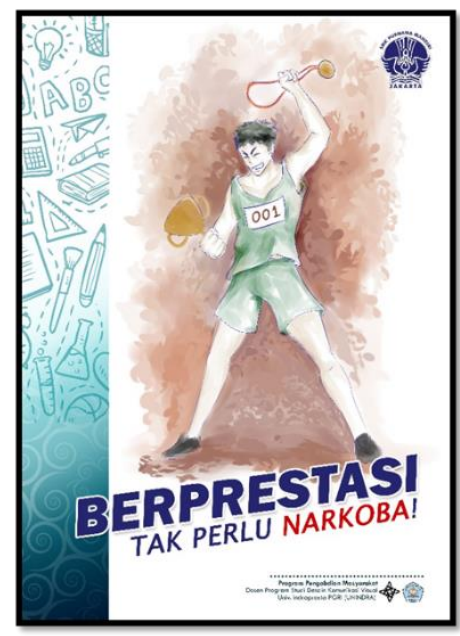

Gambar 5.6

Poster Tentang Narkoba Sumber: Dokumen Pribadi 


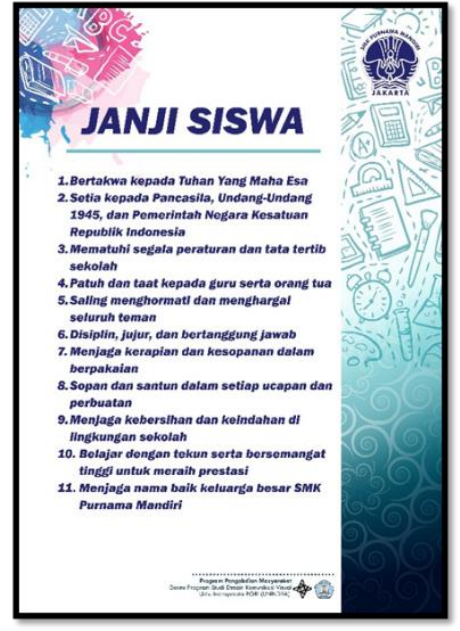

Gambar 5.7

Poster Janji Siswa

Sumber: Dokumen Pribadi

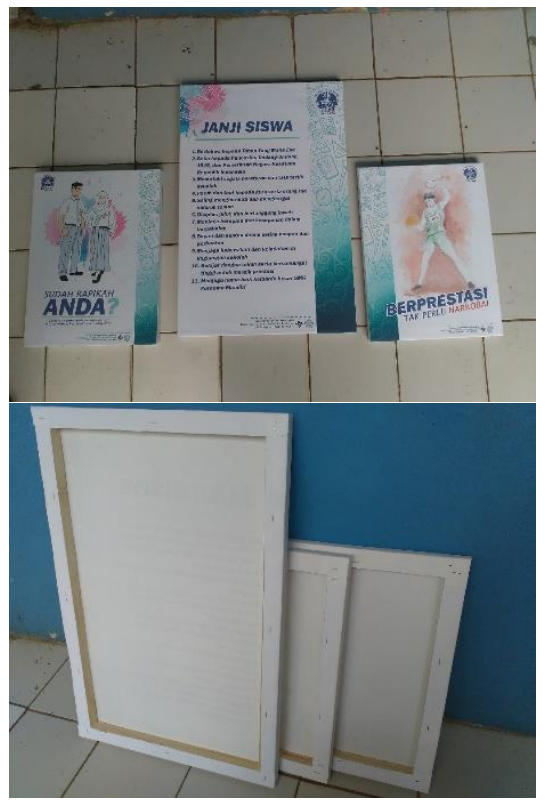

Gambar 5.8

Framing Poster

Sumber: Dokumen Pribadi

Tahap akhir dari pelaksanaan kegaiatan abdimas ini adalah penyerahan dan pemasangan poster. Penyerahan secara simbolis dilakukan oleh pelaksana dan mitra disaksikan beberapa dewan guru. Pemasangan poster mempertimbangkan beberapa hal, di antaranya adalah penyesuaian material yang digunakan untuk membuat poster (indoor/ outdoor), fokus perhatian, dan keterbacaan.

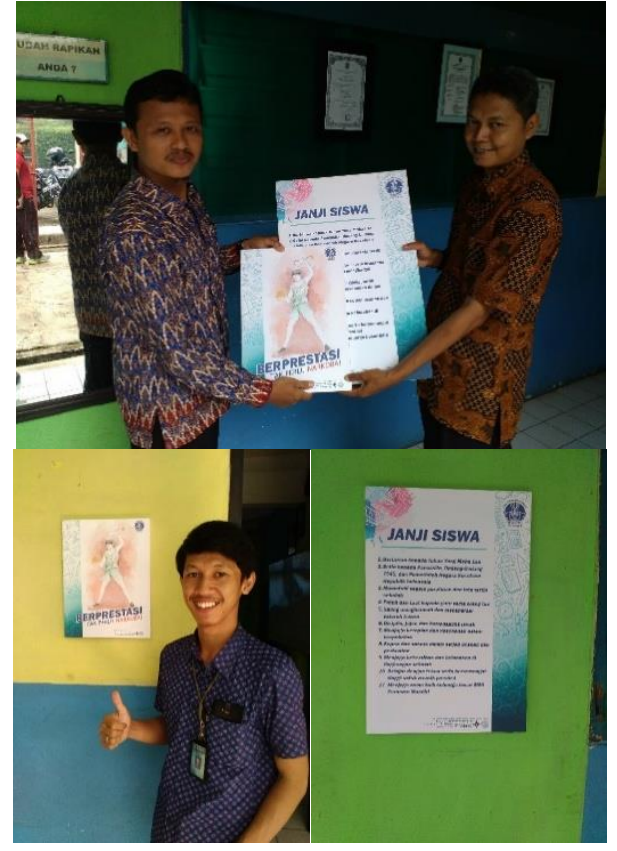

Gambar 5.9

Penyerahan dan Penempatan Poster Sumber: Dokumen Pribadi

\section{SIMPULAN}

Berdasarkan hasil pembahasan di atas dapat ditarik simpulan, bahwasannya ilustrasi yang coba diterapkan pada poster ini adalah gaya ilustrasi realistis, di mana gambar yang dibuat seperti aslinya sesuai anatomi dan proporsinya. Untuk pewarnaan, dipilih mode warna CMYK dan Pantone serta mengombinasikan mode warna tersebut dengan berbagai efek pewarnaan. Penggunaan huruf pada poster ini lebih mengutamakan readability (keterbacaan sebuah huruf) yang tinggi. Oleh sebab itu, kami memilih jenis huruf sans-serif bernama Franklin Gothic. Huruf sans-serif adalah huruf yang tidak memiliki kait/kaki dan secara kontur hurufnya, huruf ini lebih modern dibanding huruf yang memiliki serif/ kait/ kaki. Layout/ tata letak poster dipilih Picture Window Layout dimana jenis layout ini, tampilan gambar yang besar menjadi ciri khas utama dan diikuti dengan headline, keterangan gambar yang memiliki porsi yang kecil. Warna utama digunakan warna-warna dingin, 
seperti biru dan biru muda, agar tampilan poster ini lebih nyaman dipandang mata. Penggunaan teknologi dalam proses pengelolaan sekolah sangat diperlukan. Penggunaan media poster dan desain dapat membantu sekolah menyampaikan program-program prioritas. Penggunaan media yang disesuaikan dengan zamannya akan terkesan kekinian dan menarik. Media yang menarik, akan menjadi perhatian semua unsur-unsur di lingkungan sekolah, khususnya peserta didik. Penggunaan bahasanya pun bersifat pragmatis, agar bahasanya terkesan luwes atau tidak kaku. Penggunaan bahasa sesuai fungsi sintaksis tidaklah tepat digunakan dalam poster karena teks akan terlalu panjang. Melalui pertimbangan-pertimbangan tersebut di atas, target akan merasa tidak asing dengan bahasa yang digunakan karena mereka sering mendengar dan diucapkannya. Hal itu sangat sesuai karena kecenderungan komunikasi yang dilakukan dalam lingkungan sekolah adalah ragam lisan dengan laras akrab.

\section{DAFTAR PUSTAKA}

Kusrianto, A. (2007). Pengantar Desain Komunikasi Visual. Yogyakarta: Andi.

Sudjana, N. dan Rivai, A. (2002). Media Pengajaran. Bandung: Sinar Baru.

Zaimar, O. K. S. dan Harahap, A. B. (2011). Telaah Wacana Teori dan Penerapannya. Depok: Komodo Books. 